\title{
PERFILES
}

\section{Georges Haupt: vigencia de la historia del movimiento obrero y el socialismo internacional}

\author{
Hernán Camarero
}

Si el estudio del movimiento obrero y de la izquierda logró conformarse alguna vez como una expresión significativa de la historia social, política, intelectual y cultural del siglo XX, ninguna apuesta por su continuidad, a la vez crítica y renovada, puede prescindir del análisis de las distintas experiencias de elaboración personal y colectiva que lo animaron. En continuidad con este ejercicio inaugurado en el primer número de Archivos, con el examen de la figura de David Montgomery, nos dedicamos en esta oportunidad a otro gran exponente entre los historiadores del movimiento obrero. Se trata de Georges Haupt (1928-1978), de cuya precoz muerte se cumplen 35 años en el mes de aparición de esta revista. Proveniente de una familia judía húngara, de nacionalidad rumana y luego francesa, sólo una parte reducida de su vasta producción escrita en diversos idiomas fue traducida al castellano y su nombre es escasamente referenciado en el medio local. ${ }^{1}$

La relevancia de un escrutinio sobre Haupt está fundada en que no sólo permite iluminar una distinguida trayectoria intelectual individual (abonando una posible recuperación de múltiples hipótesis y enfoques metodológicos), sino también porque posibilita dar cuenta de una significativa tradición de estudios sobre el movimiento obrero y la

1. El libro con el que Haupt probablemente se hizo más conocido en nuestro país fue su colección de ensayos sobre historia del movimiento obrero y el marxismo, que acabó siendo editada después de su muerte, en varios idiomas y con diferencias de contenido. La primera versión se hizo en italiano: L'Internazionale socialista dalla Comune a Lenin (Turín, Einaudi, 1978). La adaptación francesa fue L'historien et le mouvement social (Paris, Maspero, 1980). Ésta fue vertida al castellano y publicada bajo el mismo nombre (Madrid, Siglo XXI, 1986). La más reducida fue la traslación inglesa: Aspects of International Socialism, 1871-1914. Essays (Cambridge University Press, 1986). Un catálogo parcial de la bibliografia de Haupt se hace en Rebérioux (1980: 255-268). Quizás el intelectual argentino que mejor conoció, empleó y citó al menos algunos de los trabajos de Haupt fue José Aricó. 
izquierda sobre la que nos interesa reflexionar. Si la exploración sobre Montgomery mostraba los alcances de una historia social marxista orientada a la indagación del mundo laboral en Estados Unidos (y en cierta medida en el mundo anglosajón), la de Haupt nos puede conducir a prestar atención a otra manifestación clave de nuestro campo: la que en el pasado siglo se desplegó en Francia, a través de un entramado de libros, revistas, centros de investigación, obras colectivas y proyectos diversos de elaboración teórica y, también, militante. Haupt contribuyó en estas empresas con pasión y rigurosidad.

La extensión y diversidad de su obra fue notable, siempre dentro de un continente preciso: el de la historia del movimiento obrero, el socialismo y el marxismo. Sin duda, existió un punto neurálgico en la misma, pues es considerado una autoridad indiscutida en la reconstrucción del surgimiento, transformación y crisis de la llamada Segunda Internacional, en una triple acepción: en tanto término que ocupa todo un período en la evolución del movimiento obrero (1873-1914); para definir a un tipo de movimiento obrero genéricamente aludido bajo el nombre de "socialdemócrata"; y, desde un punto de vista esencialmente institucional, como la organización socialista mundial establecida en 1889. Sin embargo, sus investigaciones se esparcieron sobre variadas temáticas: la conformación de los primeros núcleos y partidos socialistas en diferentes regiones de Europa y Asia, el bolchevismo, las ideas de Lenin y Rosa Luxemburg, la cuestión nacional en el marxismo, las consecuencias del estalinismo, la aplicación de un método sociobiográfico en el estudio de los trabajadores o la historiografia del movimiento obrero, entre otras. Además, fue un obsesivo rastreador, traductor y editor de miles de páginas de documentos sobre el tema en múltiples lenguas, labor que encaró con una auténtica erudición filológica. Y ello se explica por un convencimiento: para él, "el movimiento obrero debía enfrentarse a su propia historia sin reservas mentales", y "el punto de partida de esa búsqueda era la publicación completa y sin censura de su propio registro documental" (Montgomery, 1979: 1).

Esta empresa intelectual y política representada por Haupt, con su conjunto abigarrado de escritos y de ideas, nos parece que amerita y requiere ser examinada, con el objetivo de extraer balances e insumos fértiles para coadyuvar en nuestros propios anhelos por consolidar, finalmente, un campo de estudios sobre el movimiento obrero y la izquierda en nuestro país. ${ }^{2}$ Para contextualizar históricamente este análisis se nos

2. A pesar de la gran cantidad de referencias bibliográficas a las que recurrimos, por cuestiones de espacio tuvimos que prescindir de muchísimas otras, que consideramos menos relevantes de o sobre el autor. Cuando fue posible, privilegiamos utilizar la bibliografia de Haupt aparecida en ediciones en castellano (haciendo el señalamiento de su edición primera). Pero la mayor parte de sus publicaciones están en francés e 
impone comenzar con el recorrido de los principales tramos biográficos de nuestro autor.

\section{Itinerarios: Transilvania, Auschwitz, Leningrado, Bucarest, Paris}

La existencia de Haupt estuvo cincelada por ciertos trazos desventurados. En muchos sentidos, como sostuvo Eric Hobsbawm, la de él fue una típica "vida del siglo XX", signada por la odisea del constante cambio de estados, regimenes y culturas, con la dramática experiencia del desplazamiento de personas y el exilio forzado (1986: vii). La guerra, el nazismo y el estalinismo golpearon sobre él de manera traumática. Había nacido el 18 de enero de 1928, en Satu Mare, Transilvania, cuando la región, tras el derrumbe del Imperio Austrohúngaro, había pasado a formar parte de Rumania. Se trataba de una ciudad mediana, con población mayoritariamente húngara y una importante comunidad judía. Creció en el seno de una típica familia burguesa judía de Europa Central, lo que favoreció una formación con múltiples influencias culturales. Como lo definió el historiador Ernest Labrousse: "era internacional por vocación y por esencia", atendiendo al dato de su gran dominio de idiomas. Con naturalidad supo hablar el húngaro de su madre, el alemán de su padre, el yiddish de sus demás parientes y el rumano de sus vecinos, pero con el tiempo aprendería también, en mayor o menor medida, el ruso, el polaco, el francés, el inglés, el italiano, el serbio, el búlgaro y otros: es dificil "contabilizar el número de lenguas que finalmente Haupt leía, entendia, hablaba o escribia" (Labrousse, 1978: 217). Esta impronta le abrió luego a Haupt una ventaja decisiva para el despliegue de estudios plurinacionales y comparativos y, en especial, para la comprensión de los intercambios en el socialismo internacional (Negt, 1978: 28). Muchos historiadores reconocerian luego que, dada esta característica, a su lado se sentian un poco "provincianos" (Perrot, 1980: 34).

Su infancia y adolescencia quedó signada por la Segunda Guerra Mundial y los procesos políticos que la rodearon, en especial, la constitución del Eje nazi-fascista, que reordenó los territorios. En 1940, la zona donde se ubicaba Satu Mare volvió a ser entregada a Hungria, donde se aplicaba una clara politica antisemita. En mayo de 1944, como ocurrió con los casi 20.000 judíos de la ciudad, él y toda su familia fueron deportados a los campos de concentración nazi. Haupt estuvo recluido principalmente en Auschwitz, pero también en Buchenwald. Luego reconoció que había logrado sobrevivir en parte gracias a los únicos que

inglés, aún sin traducir. Lo mismo ocurre con la que analiza su obra. En estos casos, optamos por realizar nuestras propias traducciones de cada cita aquí transcripta. 
estaban organizados, los detenidos comunistas. Liberado por las tropas norteamericanas, se negó a seguirlas, prefiriendo retornar a Rumania, en 1945, con la esperanza de reencontrase con algún miembro de su familia. Fue allí cuando se enteró que sus padres y su hermano menor habian muerto en los campos.

Tras su regreso a Transilvania, Haupt se encontró con una nueva realidad política: el establecimiento de la República Popular de Rumania, bajo el dominio del estalinismo. La región de Satu Mare, liberada por el Ejército Rojo en octubre de 1944, había vuelto a formar parte de este país. Continuando con sus estudios, Haupt ingresó en la Universidad de Cluj, en la misma región. Su muy buen desempeño y una beca le permitieron proseguir hasta 1952 su carrera de Historia en la URSS, en la Universidad de Leningrado. Durante esa larga estancia soviética comenzó a especializarse en el vínculo entre el sudeste europeo y Rusia durante el siglo XIX. Allí sostuvo su tesis sobre la influencia de los narodniki en Rumania en el ciclo 1850-1880. Sobre estos temas y otros ligados al desarrollo del movimiento obrero y el socialismo en la zona balcánica publicó una veintena de trabajos entre 1949-1958, casi todos en idioma rumano.

Reinstalado en Rumania y ya siendo miembro activo del Partido Comunista (PC), Haupt fue alcanzando un lugar en el mundo académico: fue profesor e investigador en la Universidad de Bucarest y entre 19531958 se desempeñó como director de la Sección de Historia Moderna y Contemporánea del Instituto de Historia de la Academia de Ciencias. Al mismo tiempo, se destacó como impulsor de la revista de historia Studii (Estudios) y redactor responsable del tercer tomo del Tratado de Historia de Rumania, mientras que sus actividades científicas en otros países (Hungria, Checoeslovaquia y Polonia) se hicieron más frecuentes. Hay aquí aspectos controversiales o algunas veces pasados por alto en ciertas evocaciones dedicadas a su figura, en relación a su lugar respecto al régimen estalinista rumano. Lo cierto es que en esos años Haupt fue responsable de la cátedra de historia de la escuela del Comité Central del partido y, en la práctica, una suerte de "historiador oficial".

Sin embargo, a pesar de que había sido formado en el marxismo por algunos maestros soviéticos, a los que incluso admiraba, hacia mediados de la década de 1950 se fue experimentando en Haupt un creciente rechazo al estalinismo. En Budapest desde 1956 se vinculó al disidente Circulo Petöfi y a ex colegas de Leningrado, con los que discutió el nuevo ciclo abierto con el XX Congreso del PCUS y las denuncias sobre los crimenes de Stalin, hasta que en octubre sobrevino la invasión soviética a Hungría. En Rumania sufrió el hostigamiento: dadas sus responsabilidades, el CC del PC le exigió luchar contra la "sobrevivencia de la ideologia burguesa y el revisionismo" y que regimentara a sus colegas. 
Se negó y fue entonces cuando comenzó a pensar en irse del país. Estableció vínculos con Jean Maitron, estudioso del anarquismo, en ese entonces director del Institut Français d'Histoire Sociale y de L'Actualité de l'Histoire, revista dedicada al movimiento obrero y la única de esa disciplina que podía ingresar a Rumania. Finalmente, su emigración se produjo dos años después, en julio de 1958, aprovechando el permiso otorgado a él y a su esposa, la historiadora del arte Ruth Fabian, para efectuar un viaje por el Mediterráneo. Ambos decidieron la fuga hacia Francia, donde solicitaron asilo político y se instalaron en París, con certificados de refugiados, obligados a iniciar una nueva vida, sin recursos y con escasas relaciones locales. Una de las principales fue la de Maitron, que les consiguió la posibilidad de obtener las primeras actividades rentadas (Maitron, 1980: 31-32).

La vida de Haupt, en su nueva residencia, dio un vuelco significativo. La elección del sitio no era fortuita y no tenía necesariamente que ver con la tradicional impregnación de la cultura francesa en Rumania. En el país galo el estudio de la historia del movimiento obrero ya había consolidado un lugar en el ámbito universitario. Un antiguo surco en estas temáticas habian abierto Georges Bourgin y Édouard Dolléans, entre otros, con sus publicaciones y líneas de investigación desde el Institut d'Histoire Sociale. Y ello se hacía desde una perspectiva más o menos crítica y atenta a las reglas del oficio, es decir, distinta de la que Haupt había incursionado en Rumania, donde sus abordajes históricos habian quedado amenazados de convertirse en discurso al servicio de los intereses del Estado. Aunque con constantes viajes y estadías en diferentes países de Europa y Estados Unidos, fue en París donde vivió hasta su muerte y desplegó su más profusa y elaborada producción intelectual. Al poco tiempo, en enero de 1960, él y su mujer fueron contratados por el Centre d'Études sur l'URSS et l'Europe Orientale, perteneciente a la École Pratique des Hautes Études (luego, École des Hautes Études en Sciences Sociales, EHESS).

En Francia, la actividad de Haupt en el campo de la escritura, la preparación de volúmenes documentales y la labor de dirección editorial, siempre acerca de la historia del movimiento obrero, el socialismo y el marxismo, fue notable. En junio de 1962 defendió una tesis sobre la Segunda Internacional en la Universidad de París, bajo la dirección de E. Labrousse, el destacado historiador económico y social, con quien ya había estrechado lazos de confraternidad. Y en ese mismo año se incorporó al Comité de Redacción de Le Mouvement Social, en donde publicó una gran cantidad de artículos y fue un punto de referencia ineludible. ${ }^{3}$ La revista había sido fundada por Maitron en 1960, como

3. Le Mouvement Social consagró un número especial, aquí examinado, de revisión 
continuación de L'Actualité de l'Histoire y apoyándose luego sobre un nuevo instituto, el Centre d'Histoire du Syndicalisme. Todo ocurría en el clima de radicalización ideológico-política generado por el repudio a la guerra colonial en Argelia. De inmediato la publicación se convirtió en acicate de una renovada historia social del movimiento obrero y la izquierda francesa e internacional (Robert, 1988; Ceamanos Llorens, 2004). Alli, Haupt pudo vincularse a un amplio y heterogéneo conjunto de militantes e investigadores en estas temáticas, entre las que se destacaban varias mujeres, la mayoría discípulas de Labrousse, como Madeleine Rebérioux, Michelle Perrot, Rolande Trempé y Annie Kriegel (antes de su giro derechista). Con Rebérioux, Haupt encaró varios trabajos comunes; ella, integrante del PCF hasta su expulsión en los años 60 y especialista en la historia del socialismo francés y de Jean Jaurès, ofició, tras el retiro de Maitron, como directora de la revista entre 1971-1982. A partir de 1963 Haupt también se incorporó al comité de redacción de la revista Cahiers du monde russe et soviétique. Asimismo, desde la década de 1960, impulsó y dirigió la "Bibliothèque socialiste", una colección de libros y ensayos bajo el sello de Maspero (una de las más importantes editoriales de la izquierda francesa en la época), que evocaba a la colección del mismo nombre editada a comienzos del siglo XX por la editorial Georges Bellais. Y desde 1967 fue miembro del consejo de administración de la Société d'études jaurésiennes, fundada ocho años atrás por Labrousse. ${ }^{4}$

En Haupt hubo un intento constante de articular el compromiso político con la inserción académica. A partir de 1969, fue director de estudios en la EHESS y desde 1976 lo fue del Centre d'Études sur l'URSS et l'Europe Orientale. En la enseñanza superior impartió clases en diversas universidades, no sólo de Francia sino también como profesor visitante de otras: Wisconsin, Northwestern, SUNY at Binghamton, Libre de Berlin, Roma, Zurich. Pero esa actividad académica pretendió hacerla dilatando hasta el máximo posible los límites de "tolerancia" de esta última, sin perder cierta dimensión militante de su práctica intelectual. Un alumno de sus seminarios lo recordaba como alguien "para quien la historia del movimiento obrero no era ni un campo de maniobra antisocialista para la legitimación de la hegemonía burguesa, ni un instrumento de manipulación, sino, como él decía, el intento de permitirle a la clase obrera,

de su figura: Georges Haupt parmi nous (abril-junio de 1980). Ello ocurrió cuando la revista ya estaba en un viraje hacia posiciones menos militantes y alejadas de las problemáticas específicas del movimiento obrero.

4. La revista de esta entidad, Cahiers Jaurès, también dedicó un número completo, el de principios de 2012, a analizar la obra y trayectoria de Haupt. 
en una perspectiva emancipatoria, comparar su experiencia cotidiana con su propio pasado" (Vuilleumier, 1980: 68).

Su muerte aconteció de manera súbita, producto de un ataque al corazón, y en ella no se descarta que haya incidido una dolencia contraída de joven en los campos de concentración nazi. Ocurrió en el aeropuerto de Roma, el 14 de marzo de 1978, cuando apenas tenía 50 años y una enorme cantidad de proyectos incumplidos. ${ }^{5}$ Entre otros, se hallaba colaborando con Hobsbawm y otros investigadores en la preparación de la ambiciosa Storia del marxismo, que Einaudi finalmente editó en cinco tomos entre 1978-1982. También preparaba la publicación de la correspondencia inédita sostenida entre los rusos Gorky, Bogdanov y Lunacharsky. Y estaba su proyecto de biografia sobre el revolucionario búlgaro y oposicionista de izquierda al estalinismo Christian Rakovsky (al que tanto admiraba), así como su edición de las memorias de Charles Rappoport, una de las figuras fundadoras y luego disidentes del PC francés, que se publicarian en 1991. Analicemos ahora las contribuciones más importantes de sus obras.

\section{Para una nueva historia de la II Internacional y del socialismo}

Como antes señalamos, fue en el análisis de la II Internacional y, más en general, del movimiento socialista de fines del siglo XIX y principios del XX en donde Haupt alcanzó su máximo nivel de especialización y un reconocimiento como "pionero", por el método de formulación y abordaje del asunto (Dreyfus, 2012; Candar, 2012). Dos obras clave en este sentido fueron La Deuxième Internationale, 1899-1914. Étude critique des sources. Essai bibliographique (1964) y Le Congrès manqué. L'internationale à la veille de la première guerre mondiale (1965), ambas dotadas de un extraordinario registro documental. En una línea más específica se destacó La Deuxième Internationale et l'Orient (1967), una obra colectiva, dirigida junto a M. Rebérioux, en donde se compilaron fuentes y estudios referidos a la relación entre la socialdemocracia y la cuestión colonial-nacional en Asia y África. Y también en el plano de la edición, el extenso volumen Bureau Socialiste International: comptes rendus des réunions, manifestes et circulaires. Vol. I: 1900-1907 (1969). Para encarar muchas de estas investigaciones fue decisivo el acceso a los archivos del BSI en Amberes, que habia guardado el dirigente social-

5. En la Fondation Maison des Sciences de l'Homme se encuentra el "Fondo Georges Haupt", que reúne los materiales dejados por él en sus investigaciones en progreso: documentos y manuscritos en francés, alemán, ruso y búlgaro, recabados en archivos de Ámsterdam, Berlín, Bruselas y Viena. 
demócrata belga (y primer ministro en la posguerra) Camille Huysmans, quien se había desempeñado como secretario de la II Internacional entre 1905 y 1922. Haupt ganó su confianza y pudo analizar y reproducir estos materiales en extenso. A estas publicaciones se agregaron otras: una gran cantidad de prefacios a la edición de las resoluciones de congresos de la Internacional, como los de Copenhague (1910), Basilea (1912) y Estocolmo (1917); compilaciones de fuentes y consideraciones sobre diversos movimientos obreros y socialismos nacionales (Rumania, Bulgaria, Turquia, Suiza, Grecia); artículos sobre asuntos específicos, por ejemplo, su perspicaz estudio sobre las complejas relaciones entre partidos y sindicatos en el socialismo europeo de principios de siglo XX (Haupt, 1981).

En todos esos textos, recreó el modo en que la II Internacional logró materializarse a partir de julio de 1889 en París, sin que su existencia fuera reconocida oficialmente sino hasta diez años más tarde, con la creación del BSI en 1900. Las paradojas se acentuaron pues el nombre de II Internacional no apareció allí sino después. Se oficializó en su momento de mayor crisis, agosto de 1914, cuando muchos la creían políticamente enterrada por la crisis generada con la guerra. Y adquirió un sentido simbólico, pues fue hecho a 50 años de la fundación de la Asociación Internacional de Trabajadores (AIT), fundada en Londres en 1864, como su pretendida continuación. Los avatares siguientes complejizaron esta nominación. Siguió manteniéndola cuando la entidad se reconstituyó en 1919 en Berna, pero dos años después una unión de partidos socialistas conformada en Viena pasó a conocerse como "Internacional dos y media". La fusión de ambas en 1923 dio vida a la "Internacional obrera socialista", que se expandió en los años posteriores. Para la izquierda revolucionaria (Rosa Luxemburg, Lenin, Trotsky), la II Internacional era el apelativo del oportunismo, el reformismo y la traición a los principios. Y de alli la necesidad de erigir con rapidez una III Internacional, también amparada en los genuinos valores de la AIT. La disputa por la herencia era evidente. Haupt denunciaba la obra mistificadora de la Comintern en proceso de estalinización, que, con el objetivo de asegurar su hegemonía, montó una campaña de falsificación sobre la II Internacional y la tradición que encarnaba. Ella coaguló un estereotipo, con dos fases contrapuestas: la revolucionaria, cuya continuidad se aseguraba con la presencia de Engels; y, luego de la muerte de este último, la etapa de degeneración en el oportunismo y la traición (1986a: 2-5).

Sobre lo que Haupt alertaba era acerca de los caminos por los cuales la experiencia de la II Internacional habia quedado alejada de una comprensión historiográfica y teórica certera, sin consulta fidedigna de fuentes primarias. Sólo imperaban visiones maniqueas y polémicas ideológicas entre pretendidos o legitimos herederos del proyecto de 
una organización mundial de los trabajadores. Desde mediados de la década de 1950, en parte por la creciente crisis del estalinismo, Haupt observaba que la historia de la II Internacional había ido perdiendo el contenido pasional y la función ideológica que la obturaba. Comenzaba a desbrozarse un nuevo camino de descripciones y ejercicios de sintesis más cuidados, como los de James Joll, G.D.H. Cole, Amaro del Rosal, Julius Braunthal y otros. Haupt quería filiar su empresa historiográfica en la senda ya abierta por esa generación de investigadores, pero alejándose de la agenda más bien antileninista de éstos, incorporando su perspectiva de historia social marxista y la novedad de su enfoque metodológico, que cuestionaba las limitaciones más agudas presentadas por estas nuevas historias, que él denominaria "tradicionales". Su proyecto de renovación se afincó desde un comienzo en un intento por proponer algo que fuera más allá de hacer una mera "historia de la Internacional socialista"; su apuesta fue extender y complejizar el análisis para conducirlo a una "historia internacional del socialismo", ampliando la problemática y el marco conceptual en que este último pudiese entenderse. Sobre estas cuestiones teóricas y metodológicas ya había girado uno de sus primeros artículos en Le Mouvement Social (1962: 16). En su opinión, en la que se advierte la influencia de los enfoques desplegados por el historiador italiano Giuliano Procacci, se trataba de sortear visiones institucionalistas e ideologistas sobre el movimiento obrero mundial entre 1889 y 1914, que tendian a considerarlo a partir de una enumeración de reuniones, debates y resoluciones de la Internacional o desde el ángulo exclusivo de sus postulados dogmáticos. El peligro de esta concepción, según Haupt, era que así se subordinaba la historia del movimiento obrero y del socialismo a la primacia de las doctrinas, aislándolas del análisis de la sociedad en la cual ellas cobraron vida, de la lucha de clases y del protagonismo de los trabajadores: "La cuestión es precisamente no disociar al socialismo, como movimiento e ideología, de la acción colectiva organizada del proletariado del cual éste se reclama" (1962: 9).

Por otra parte, Haupt rechazó cualquier indagación sobre la II Internacional que no contemplara la heterogeneidad de posiciones que la surcó; tampoco creía que ésta pudiera vislumbrarse como una simple yuxtaposición de la historia de los diversos partidos socialistas nacionales, anulando la potencialidad del más útil método comparativo. El desafio consistía en superar el límite geográfico en el que el tema había sido estudiado, es decir, el de las sociedades industriales de Europa Occidental y Central, olvidando la progresiva extensión que el movimiento socialista comenzó a experimentar en regiones como la Europa mediterránea, Rusia, los Balcanes, Estados Unidos, América Latina, Australia y diversos países asiáticos. El otro problema era el temporal: 
se había subestimado el necesario arco de larga duración en que el fenómeno debía ser examinado (1873-1914) y no se había reconocido la especificidad de sus distintos períodos. Al menos de los dos grandes que podian señalarse: el situado entre la disolución de la AIT y la "crisis revisionista" de fines del siglo XIX, que señala a una organización mundial aún en plena faena de configuración; y el comprendido desde ese proceso hasta 1914, signado por la gran expansión y modernización organizativa de los partidos que la integraban, su clara separación del gremialismo, la creciente moderación reformista de sus direcciones y la profundización de la división ideológico-política del movimiento. Esto último invitaba a atender tanto las disputas entre marxistas ortodoxos, izquierdistas radicales, sindicalistas revolucionarios o revisionistas como las particularidades existentes entre el poderoso Partido Socialdemócrata Alemán (SPD), el socialismo y sindicalismo francés, el trade unionism británico, el movimiento revolucionario ruso, el austro-marxismo o el partido belga. Todos ellos traducian, a su modo, la diversidad de los movimientos obreros y de las sociedades en las que actuaban. Para Haupt la clave era capturar esta articulación compleja entre la visión de conjunto de la socialdemocracia mundial (lo que él llamaba plano de análisis "horizontal") con las particularidades de los "prototipos nacionales" (plano "vertical") y, más globalmente, era imperioso concebir a la II Internacional "no como una institución o una simple federación sino como la expresión fundamental de una época en la evolución de la historia obrera y socialista" (1962: 33).

Dentro de este escenario, ¿cómo proyectó el SPD su influencia en el seno de la Internacional desde los años 1880? La novedad del enfoque de Haupt estuvo en que buscó explicar las causas y funcionalidad de esa hegemonía sin reducir el problema a una simple cuestión de "modelo imitado" o "injerto". Intentó desentrañar por qué las otras secciones, sobre todo las de menor consistencia, aceptaban ese papel dirigente de los germanos y sentían la necesidad de un "partido-guia", es decir, sobre qué bases se fundaba su lealtad. Con este objetivo, consagró un estudio específico a los casos del sudeste europeo, en concreto, al incipiente movimiento socialdemócrata que se fue conformando desde 1890 en Bulgaria, Rumania y Serbia, países caracterizados por economías atrasadas y débil proletariado. Precisaba:

A través del gran partido alemán, sus epígonos balcánicos definen su propia identidad; su ejemplo, su prestigio, contribuyen a afianzar en el sudeste europeo un estado de ánimo socialdemócrata militante, combativo, riguroso e intransigente en cuestión de principios. (1986 e: 111) 
Esa imagen idealizada del SPD habría sido ayudada por instrumentos de difusión y canales para la penetración de ideas (contactos militantes, medios de prensa, labor de propaganda y educación a partir de la literatura), y reforzada por el ascendiente de los intelectuales y dirigentes de aquel partido, como Bebel, Luxemburg y, sobre todo, Kautsky (cuya correspondencia con los cuadros balcánicos Haupt estaba en vias de editar al momento de su muerte). Y concluyó esbozando las circunstancias en las que ese respeto se resquebrajó con las posiciones que el SPD asumió frente a la guerra mundial y la revolución rusa y las razones por las cuales acabó siendo reemplazado por dos nuevos focos de atracción: el bolchevismo ruso y el austromarxismo.

Encontramos en Le Congrès manqué (1965) un libro clave de Haupt, no casualmente uno de los que tuvo más revisiones y publicaciones en otros idiomas (aunque no en castellano). El interés por este tema se prolongó luego en otros textos, como el artículo "¿Guerra o revolución? La Internacional y la 'Unión sagrada' en agosto de 1914” (1986f: 146179). Sobre todo en su libro, analizó en detalle lo que debió haber sido el X Congreso Socialista Internacional a reunirse en agosto de 1914 en Viena. Allí se esperaba que la Internacional fijara una definición sobre los objetivos de su actividad durante los tres años siguientes y acerca de los medios para evitar la inminente guerra continental, en especial, a través de una huelga general simultánea y universalmente organizada (como había ocurrido dos años antes en el congreso del SPD). Pero ese cónclave tan minuciosamente preparado no tuvo lugar, claro, con el inicio de la conflagración europea, lo que condujo al derrumbe del cincuentenario edificio de la organización.

El internacionalismo retórico no resistió la prueba. Las resoluciones adoptadas en los anteriores congresos quedaron en letra muerta. El 4 de agosto la fracción socialdemócrata del Reichstag votó los créditos de guerra, el presidente de la Internacional Vandervelde entró en el gobierno belga y en Francia triunfó la Unión sagrada. (1965: 10)

El desafio era reconstruir el "clima psicológico y las motivaciones teóricas" del socialismo y comprender cómo llegó al momento del conflicto bélico sin caer en la tentación de tomar posición sobre los hechos desde las "experiencias posteriores al 4 de agosto", relatadas en base a los actores contemporáneos (1965: 12-15). E intentar explicar el "hundimiento de la Internacional" más allá de las meras alusiones a "la impotencia, el viraje o la traición", pues, en definitiva, "la guerra concreta un renunciamiento que viene de muy antiguo, encierra a la Internacional en sus propias contradicciones y la arrincona en un callejón sin salida" 
(1986 f: 179). Se desconocían datos vitales: lo que había pasado en la Internacional entre el Congreso extraordinario de Basilea (noviembre de 1912) y agosto de 1914; o que el Congreso a reunirse en Viena en esa última fecha no sólo debía pronunciarse acerca de la huelga general sino también sobre el análisis del imperialismo y sobre la política socialista en función de ello. Con estos objetivos, Haupt decidió reunir en un volumen todos los textos impresos para ese cónclave pero que nunca habian sido distribuidos ni difundidos (se hallaban en el Instituto de Historia Social de Ámsterdam), agregándole otros documentos manuscritos de los archivos del BSI.

\section{Contribuciones al estudio del marxismo, el bolchevismo, Rosa Luxemburg, la cuestión nacional y la historiografia del movimiento obrero.}

Haupt realizó aportes en otras temáticas que nos interesa explorar. Se destacó la compilación y examen que hizo de la correspondencia, en gran medida inédita, intercambiada de 1905 a 1914 entre el entonces delegado ruso Lenin y el secretario del BSI Camille Huysmans (Haupt, 1963). Con esta obra, "un precioso trabajo de restauración", como lo elogiara el historiador trotskista Pierre Broué (1965: 146), se liberaron de ciertas tergiversaciones las relaciones sostenidas entre los bolcheviques y la Internacional en la preguerra y, más en general, el modo en que el Bureau se vinculó con el Partido Obrero Socialdemócrata Ruso. Más relevante aún, se brindaron pistas para modular la incomprensión que el BSI evidenciaba frente a las discusiones que sacudian al POSDR. También se registró el endurecimiento de la posición leninista, sin que se encuentren en los intercambios una "hostilidad declarada" o elementos que hagan suponer la futura total ruptura entre ambos, lo que finalmente sí ocurrió con la cuestión de la guerra. Algunas de estas conclusiones fueron propuestas en su artículo "Lenin, los bolcheviques y la II Internacional" (1986d: 65-102). Asimismo, una contribución valiosa fue el volumen preparado junto a otro historiador trotskista francés, Jean-Jacques Marie, Les Bolchéviks par eux-mêmes (Haupt-Marie, 1969), que recopiló los relatos autobiográficos de los principales cuadros bolcheviques, extendiendo así el examen social, político e ideológico de la corriente revolucionaria rusa. En su artículo "Guerra y revolución en Lenin", reconstruyó cómo esa temática fue abordada desde "la complejidad del pensamiento y de la práctica" del líder revolucionario ruso, desechando la búsqueda de "preceptos" o teorias fundadas en la dialéctica de aquellos dos términos, fuera de "la política realista exigida por la acción" (1986g: 181-182).

La edición y análisis crítico, en dos volúmenes, de la correspondencia 
de Rosa Luxemburg (Luxemburg, 1976 y 1977) fue otro proyecto valioso dirigido por Haupt, el cual permitió recuperar aspectos poco conocidos de la vida personal y política de la revolucionaria polaca. El interés de Haupt por esta figura fue creciente. En parte, ello explica la intensa relación que, desde mediados de la década de 1960, estableció con Lelio Basso. Desde sus diversos trabajos y su revista Problemi del socialismo, fundada en 1958, este intelectual y dirigente politico socialista italiano venía incursionando en reflexiones sobre el devenir del marxismo. Encontró en Haupt a uno de sus principales interlocutores teóricos fuera de Italia. Ambos forjaron una amistad basada en sus comunes preocupaciones ideológicas e historiográficas, su similar lectura de Marx en clave antidogmática y antiestalinista, inspirada por una recuperación de la perspectiva de Franz Mehring, pero sobre todo por su misma revalorización de la trayectoria e ideas de Luxemburg (Fondation Lelio Basso, 1980: 45; Salvati, 2012: 27-48). ${ }^{6}$ Haupt la rescató como expresión de un socialismo revolucionario alternativo y, en particular, se interesó en explorar su caracterización del problema nacional en todos sus momentos de despliegue (1893-1897, 1902, 1906, 1908-1909, 1915, 1918), que la condujo a lo que él denominó "un internacionalismo intransigente" (ver Löwy, 2012: 111-119). Reconoció en Luxemburg la virtud de haber sido precursora, entre los marxistas de la II Internacional (incluso antes que Lenin), en replantear el problema nacional (1979).

Por las obvias razones de su biografia, Haupt dedicó atención al asunto de las nacionalidades. Alguien escribió: "Se convirtió en internacionalista y humanista cuando quedó atrapado entre las llamas del nacionalismo", en su período húngaro-rumano (Jemnitz, 1980: 49). En un trabajo en coautoría (Haupt y Weill, 1980a) y sobre todo en el libro Los marxistas y la cuestión nacional (Haupt, Löwy y Weill, 1982) se trazó el objetivo de auscultar el modo diverso y complejo en el cual el socialismo clásico había abordado el problema. Alli se recopilaron y revisaron trabajos de Marx, Engels, Kautsky, Luxemburg, Lenin, Stalin, Bauer, Renner, Strasser y Pannekoek, entre otros, contextualizándolos y examinando las transformaciones que exhibió dicha tradición, desde las primeras alusiones a la idea de "pueblos sin historia" (en este punto, continuando observaciones de Roman Rosdolsky) y desde las enunciaciones casi social-darwinistas a los más sofisticados planteos del autromarxismo. Aludía a un camino de elaboración con generalizaciones prematuras y fuertes divergencias entre lo que él llamaba "el dinamismo y el conser-

6. Se encontraron juntos en iniciativas de edición, coloquios y seminarios de investigación en Italia y Francia, referidos al pensamiento marxista, el movimiento socialista y las posiciones de Luxemburg. Las cartas conservadas en la Fondazione Lelio e Lisli Basso atestiguan ese intercambio. Haupt se convirtió en colaborador y miembro de dicha entidad, inaugurada en 1973 en Roma. 
vadurismo de la ideología". Dentro de aquel libro, el texto de Haupt ("Los marxistas frente a la cuestión nacional: la historia del problema"), era el que ubicaba con más amplitud las dificultades para comprender la diversidad de posiciones que habia recorrido el marxismo. Como sostuvo Löwy (1998: 92), Haupt era uno de los que más habian alertado acerca de la importancia de la contribución del austromarxista Otto Bauer, con su libro La cuestión de las nacionalidades y la socialdemocracia (1907), en donde se planteaba la complementariedad entre la autoemancipación y la autonomía nacional-cultural. Al análisis de sus planteos le había dedicado algunos ensayos específicos (1976). No obstante, advertimos que sus contribuciones estuvieron más bien dirigidas a pensar cómo el marxismo y el movimiento obrero se ubicaron frente a este dilema, antes que a realizar una exploración profunda y global de la cuestión de la nación y el nacionalismo, lo que sobrevendría desde la década siguiente a su muerte, con la aparición de importantes obras, como las de Benedict Anderson o Ernest Gellner, entre muchas otras.

En todo caso, las reflexiones acerca del carácter heterogéneo y plural del marxismo, en general y no sólo frente al problema nacional, fueron algunas de las que despertaron mayor interés en Haupt en sus últimos años, como puede advertirse en su ensayo finalmente aparecido en uno de los tomos de la obra colectiva Historia del marxismo (1980b). Allí, en sintonía con reflexiones como las de Maximilien Rubel, retomó el planteo que tendía a historizar y distinguir los términos "marxista" y "marxismo", es decir, entre las ideas vivas y complejas del pensador alemán y su conversión en doctrina. De este modo, encontró el surgimiento del marxismo como ideología sistematizadora hacia fines del siglo XIX, postulando que, en ese sentido, la labor de Kautsky y Bernstein, entre otros, había sido central, en tanto impulsores de la idea de identificar el carácter esencial del marxismo como ciencia en la concepción materialista de la historia.

Hubo otra producción intelectual de Haupt a ponderar. Maitron venía desplegando una labor de gran aliento desde 1955: la edición de un Dictionnaire biographique du mouvement ouvrier français, que tras varias décadas de trabajo y decenas de volúmenes publicados acabó cubriendo en el análisis todo el período 1789-1939, con miles de entradas biográficas producidas por centenares de historiadores obreros de por lo menos tres generaciones. Sobre la base de esta extraordinaria experiencia, Haupt colaboró con él en otro proyecto ambicioso que se comenzó a desplegar a partir de los años 70: la edición de un Dictionnaire biographique du mouvement ouvrier international en múltiples tomos. A su cargo estuvo el primero de ellos en aparecer, el dedicado a Austria (Maitron y Haupt, 1971). La de los diccionarios fue una apuesta por ensayar una prosopografia obrera que abonaba 
la construcción de una historia social de los trabajadores, siguiendo sus recorridos de vida.

Por último, nos detendremos en las consideraciones de Haupt acerca de la historiografia del movimiento obrero. Uno de sus últimos artículos estuvo dedicado a ello, donde despunta un balance del propio campo (1986b). Los motivos para ser optimista, decía, eran reales: desde los años 60 la historia obrera, antes desvalorizada o negada, había logrado consolidarse, incluso, en la propia academia. Su renovación teórica y metodológica la había alejado de una mera dimensión ideológica e institucionalista, para conducirla hacia los senderos de una genuina historia social. Contribuia a este afianzamiento la obra de referentes (E.P. Thompson, Eric Hobsbawm, Rolande Trempé, Michelle Perrot, entre otros) y el vigor aportado por una pléyade de nuevos estudiosos, grupos de investigación y revistas. Pero los riesgos del estancamiento estaban presentes, así como el reclamo de retorno de los viejos relatos de pasado heroico e idealizado. Sobrevolaba la perspectiva de Lukács, cuando reconocía que "ningún movimiento social tiene tanto apego a su propia historia como el movimiento obrero, ninguno siente tanto la necesidad, incluso el imperativo, de unir el pasado al presente. La clase obrera, postulada clase teleológica, tiene necesidad de la conciencia histórica y, por lo tanto, del conocimiento de su pasado para cumplir su misión" (1986b: 14). Pero divisaba una tensión entre dos posibles utilizaciones de esta historia. Una de ellas era en cuanto "praxis", o sea, laboratorio de experiencias y campo de elaboración teórica-estratégica, donde imperaba el rigor y el espíritu crítico: testimonio de ello fueron los recurrentes señalamientos de Marx o Luxemburg acerca del modo en que la experiencia histórica de los fracasos y victorias de los trabajadores eran una vital fuente de su conocimiento. La otra era en cuanto "tradición", es decir, como fuente de legitimidad y argumento ideológico para la cohesión colectiva y subordinada a los imperativos de la acción. ${ }^{7}$

En relación a la tradición historiográfica militante, Haupt detectaba una tensión entre la pasión por la investigación y el respeto por la verdad que guiaba a sus representantes (algunos tan ilustres como Guillaume, Nettlau, Puech, Jaeckh, Mehring o Riazánov) y su tendencia a subordinarse a su parti pris ideológico (bakuninista, proudhoniano o marxista). La máxima distorsión creada por la "historia-tradición" las encontraba

7. Sus indagaciones acerca de la "función ideológica de la historia" en el movimiento obrero, escudriñando las maneras en que se construyeron las memorias colectivas, se erigieron los símbolos y se transmitieron las banderas, son sugerentes. Por ejemplo, cuando reflexiona sobre la Comuna de París y exhibe los mecanismos por los cuales cada tendencia, desde Marx y Bakunin, pretendió rodearse de la "aureola de 1871", proclamándose como su única heredera legítima y como síntesis de sus aspiraciones (1986c: 36). 
en aquellas "leyendas arraigadas del partido", de las que emanaba un historicismo moralizador y banal, instrumento de autojustificación:

La historia del movimiento obrero erigida en ideología, adecuada a la didáctica, manipulada, vaciada de su savia mediante el uso de un lenguaje estereotipado, hace perder interés por la época y atrofia la memoria colectiva de la clase obrera. (1986 b: 17)

Un contraejemplo era Mehring, quien por su competencia teórica y espíritu científico quedaba referenciado como digna expresión de la historia militante, pues no rechazaba el presente como motivación del pasado, sino su mera proyección, comprendiendo las diferencias entre las exigencias del momento de la clase o el partido y la verdad histórica. Pero este potencial camino para una historia obrera crítica, emancipada de ejercicios piadosos y hagiográficos, no logró proyectarse desde 1920-1930, al ser desplazada por las llamadas "historias oficiales". Ellas apuntaron a la mitologización, quedando todo reducido a una suerte de "historia-directriz", a un arma entre rivales para legitimar las pretensiones hegemónicas de los aparatos socialdemócratas o comunistas. La degradación manipulatoria llegaría a su cenit con el estalinismo:

Con la ayuda de inauditas falsificaciones, atropellando y menospreciando las realidades históricas más elementales, el estalinismo borra, mutila y remodela metódicamente el campo del pasado para reemplazarlo por su propia representación, sus mitos, su autoglorificación. La historia del movimiento obrero internacional se petrifica también en una colección de imágenes muertas, trucadas, vacías de contenido, reemplazadas por copias acicaladas donde apenas se reconoce el pasado... (1986b: 21-22)

Pero alertaba que la crisis del estalinismo no había enterrado esta tendencia a concebir la historia del movimiento obrero todavía como "ciencia de legitimación", aún por quienes se hallaban distantes de los aparatos o tradiciones socialdemócratas y estalinistas.

Hallamos en todas estas observaciones insumos para afrontar un reto en el escenario local. En pos de consolidar una historia del movimiento obrero crítica y científicamente fundada, habrá que enfrentar algunos de los obstáculos que señalaba Haupt. Y sin embargo, las peculiaridades son obvias. Por ejemplo, hoy y aquí casi no existe necesidad de ajustar cuentas con las apolilladas versiones socialistas de cuño liberal o las tipicas falsificaciones estalinistas, que cayeron en la irrelevancia por su propio peso. Los mayores adversarios, en cambio, son las historiografias 
populista y reformista: ambas naturalizan la identidad peronista de la clase obrera (revalorizándola o lamentándola), la reconocen en actitudes o itinerarios previos casi constantes y la eternizan hacia el futuro. La distorsión de esta historia-tradición, de origen "militante" y académico, es el mayor dogal de cualquier perspectiva de recuperación crítica del estudio del movimiento obrero argentino.

$$
* * *
$$

A modo de corolario, enunciemos algunos elementos generales sobre la empresa intelectual de Haupt. Nos parece que sus textos brindan criterios rigurosos y creativos para comprender el devenir de las concepciones ideológicas y de las estrategias políticas en el marxismo, así como los imprevisibles vínculos que se tejieron entre programa y realidad. En particular, destacamos la fertilidad de su modelo de análisis de la izquierda internacional de fines del siglo XIX y comienzos del siglo XX, con el que procuró capturar los modos de articulación, influencia y diferenciación entre los distintos partidos y corrientes. Ese ensayo comparativo aún nos brinda herramientas útiles para pensar las características y transformaciones de los movimientos socialistas y comunistas en América Latina. Bregó explícitamente por el derecho a la existencia de la historiografia obrera y la necesidad de que no fuera un campo académico devaluado, sino respetable y vigoroso, en base a la seriedad en el tratamiento de las fuentes y el espíritu científico (Rabinbach, 1980: 76). Su obra puede ser reapropiada, también, desde un cuadrante metodológico más global, por su impugnación a las fórmulas cristalizadas en axiomas rígidos y por su convocatoria a una actitud desconfiada frente a los modos en que el pasado suele ser remodelado para adecuarlo a imágenes transfiguradas por la ideologia y sometidas a manipulación historiográfica. En término aún más abarcadores, se ha reivindicado la combinación provechosa que en él se expresaba:

Su erudición impecable, su atención brindada tanto a las prácticas militantes como a los debates de ideas, y su gran interés por la historia en escala internacional, sin olvidar su apertura a otras disciplinas, como la sociologia, constituyen todavía pistas para los historiadores de hoy. (Ducange-Fontaine, 2012: 7).

¿Puede rastrearse su figura en ciertos arquetipos de intelectualesmilitantes, como Mehring, David Riazánov o, incluso, Arthur Rosenberg, por la manera que en ellos se combinó la rigurosidad científica y el compromiso socialista? (Rabinbach, 1980: 75). Quizás, la alusión 
no es completamente adecuada o carece de precisión en términos políticos. En todo caso, los testimonios indican que Haupt siempre mantuvo sus convicciones en la posibilidad de una sociedad sin opresión (Bezucha,1979: 454), desde un socialismo marxista con entonaciones libertarias. Precisamente, quizá resulte una tarea vana encasillarlo en alguna vertiente definida de la tradición de las izquierdas. Tras su "período rumano" se había alejado de toda forma "institucional" de marxismo y reivindicaba a éste en clave crítica, independiente y antidogmática, sin convertirse nunca en un "renegado" (Marek, 1980: 52-54; Weill, 2012: 104). Pero junto a esa cualidad cobran peso las ambigüedades. Su lúcida recuperación de figuras, proyectos o experiencias alcanzó a configurar un rico fresco pero sin ofrecer un balance sistemático que los jerarquizara y ordenara en una única o estructuralmente coherente concepción teórica-programática. Y alli las lagunas son enigmáticas. Por ejemplo, en función de sus esperanzas por descubrir otras formas de socialismo, resulta notable su escasísimo aporte al estudio del trotskismo, una corriente esencial del marxismo revolucionario, la que sacó las primeras y más relevantes conclusiones sobre el fenómeno estalinista que él tanto condenaba.

En la presentación de El historiador y el movimiento social, escrita poco antes de morir, Haupt, haciendo una suerte de recapitulación de su vida, afirmaba que los estudios alli reunidos eran "el producto de un 'combate por la historia obrera', iniciado hace dos decenios" (1986a: 8). En otro segmento de ese volumen reconocía que aquella batalla iba "mucho más allá del saber histórico" (1986b: 34). Esa funcionalidad política con la que Haupt encaraba su aventura hacia el conocimiento lo distingue como intelectual y convierte su obra y su trayectoria, más allá de ciertos intentos pasados y presentes, en algo dificil de apropiar desde una perspectiva académica aséptica, acrítica o escasamente consustanciada con los intereses históricos e inmediatos de los explotados. Al mismo tiempo, lo ponía en guardia contra las desnaturalizaciones en las que esta tarea podía caer por sectarismo y dogmatismo:

Sacrificar por consideraciones ideológicas o por rutina el estudio de una realidad multiforme, compleja y rica, equivale a sacrificar lo esencial de la historia del movimiento obrero, el conocimiento de una experiencia duramente adquirida de la que siempre se le ha privado. (1986b: 34)

Estos empeños, estas alertas y este posicionamiento teórico-político con el que Haupt abordaba el reto de hacer una historia del movimiento obrero que fuera realmente útil, por su rigor, su compromiso y su enfoque desmitologizante, mantienen toda su vigencia. 


\section{Bibliografia}

Bezucha, Robert (1979), "Georges Haupt, 1928-1978”, Theory and Society. Renewal and Critique in Social Theory, vol. VII, $N^{\circ} 3$, mayo, pp. 453454.

Broué, Pierre (1965), “Notes de lecture”, Le Mouvement Social, N 50, eneromarzo, París, pp. 145-146.

Candar, Gilles (2012), "Socialisme et International(e), militants et historiens", Cahiers Jaurès, $\mathrm{N}^{\circ}$ 203, enero-marzo, París, pp. 49-61.

Ceamanos Llorens, Roberto (2004), De la historia del movimiento obrero a la historia social. Cincuenta años de historia social en Francia (1950-2000). L'Actualité de l'Histoire (1951-1960) y Le Mouvement Social (1960-2000), Zaragoza: Prensas Universitarias.

Dreyfus, Michel (2012), "Georges Haupt, pionnier de l'histoire du socialism", Cahiers Jaurès, $\mathrm{N}^{\circ}$ 203, enero-marzo, París, pp. 13-26.

Ducange, Jean-Numa y Marion Fontaine (2012), "Avant-propos”, Cahiers Jaurès, $\mathrm{N}^{\circ}$ 203, enero-marzo, París, pp. 5-8.

Fondation Lelio Basso (1980), "Georges Haupt. Le témoignage de la fondation Lelio Basso", Le Mouvement Social, $\mathrm{N}^{\circ} 111$, abril-junio, París, pp. 45-47.

Haupt, Georges (1962), "Histoire de l'internationale socialiste ou histoire internationale du socialisme. Sur quelques controverses à propos de problèmes de recherche et de méthode", Le Mouvement Social, $\mathrm{N}^{\circ} 41$, octubre-diciembre, París, pp. 13-34.

- (1963), Correspondance entre V. Lénine et Camille Huysmans, 1905-1914. Documents recueillis et présentés par G. Haupt (prefacio de C. Huysmans), París-La Haya: Mouton, 165 pp.

- (1964), La Deuxième Internationale, 1899-1914. Étude critique des sources. Essai bibliographique, París-La Haya: Mouton.

- (1965), Le Congrès manqué. L'internationale à la veille de la première guerre mondiale. Étude et documents, París: Maspero, Bibliothèque socialiste. [Ed. ampliada: Socialism and the Great War: the collapse of the Second International, Oxford: Clarendon Press, 1972.]

- y Madeleine Rebérioux (dirs.) (1967), La Deuxième Internationale et l'Orient, Paris: Cujas.

- y Jean-Jacques Marie (1969), Les Bolchéviks par eux-mêmes, París: Maspero. [Ed. en castellano: Los bolcheviques, México, Era, 1972.]

- (1969), Bureau Socialiste International: comptes rendus des réunions, manifestes et circulaires. Vol. I: 1900-1907, París-La Haya: Mouton.

- (1976), "Présentation a Otto Bauer, 'Remarques sur la question des nationalités' (1908)”, en Pluriel-Débat, N 5, París, pp. 41-58.

- (1979), "Dinamismo y conservadurismo de la ideología. Rosa Luxemburgo y la investigación marxista sobre la cuestión nacional", en R. Luxemburgo, El desarrollo industrial de Polonia y otros escritos sobre el problema nacional, México: Cuadernos de Pasado y Presente, pp. 7-53. 
- y Claudie Weill (1980a), "Marx y Engels frente al problema de las naciones", en K. Marx y F. Engels, La cuestión nacional y la formación de los estados, México: Cuadernos de Pasado y Presente, $N^{\circ} 69$ [1 ${ }^{a}$ ed. en Studi Storici, 1974].

- (1980b), "Marx y el Marxismo", en E. Hobsbawm, N. Badaloni, L. Krader, G. Haupt y G. S. Jones (dirs.), Historia del marxismo, vol. 1, El marxismo en tiempos de Marx, tomo 2, Barcelona: Bruguera, pp. 197-233.

- (1981) "Socialisme et syndicalisme. Les rapports entre partis et syndicats au plan international: une mutation?”, en Madeleine Rebérioux y Jean-Pierre Rioux (dirs.), Jaurès et la classe ouvrière, París: Éditions Ouvrières, pp. 29-66.

-, Michael Löwy y Claudie Weill (eds.) (1982), Los marxistas y la cuestión nacional, Barcelona: Fontamara [1 $1^{\mathrm{a}}$ ed.: París: Maspero, Bibliothèque socialiste, 1974].

- (1986a), "Introducción. Historia e Internacional", en G. Haupt, El historiador y el movimiento social, Madrid: Siglo XXI, pp. 1-8.

- (1986b), “¿Por qué la historia del movimiento obrero?”, en G. Haupt, El historiador y el movimiento social, Madrid: Siglo XXI, pp. 9-34.

- (1986c), "La comuna como símbolo y como ejemplo", en G. Haupt, El historiador y el movimiento social, Madrid: Siglo XXI, pp. 35-64 [1 ${ }^{\mathrm{a}}$ ed. en Le Mouvement Social, 1972].

- (1986d), "Lenin, los bolcheviques y la II Internacional", en G. Haupt, El historiador y el movimiento social, Madrid: Siglo XXI, pp. 65-102 [1 ${ }^{\mathrm{a}}$ ed. en Cahiers du monde russe et soviétique, 1966].

- (1986e), "El partido-guía: la irradiación de la socialdemocracia alemana en el sudeste europeo", en G. Haupt, El historiador y el movimiento social, Madrid: Siglo XXI, pp. 103-145.

- (1986f), “¿Guerra o revolución? La Internacional y la 'Unión sagrada' en agosto de 1914", en G. Haupt, El historiador y el movimiento social, Madrid: Siglo XXI, pp. 146-179 [1 $1^{\mathrm{a}}$ ed. en Les Temps Modernes, 1969].

- (1986g), "Guerra y revolución en Lenin", en G. Haupt, El historiador y el movimiento social, Madrid: Siglo XXI, pp. 180-206 [1 $1^{\mathrm{a}}$ ed. en Revue Française de Sciences Politiques, 1971].

Hobsbawm, Eric (1986), "Preface", en Georges Haupt, Aspects of International Socialism, 1871-1914. Essays, Cambridge University Press, pp. vii-xvii.

Jemnitz, Janos (1980), "Georges Haupt. Le feu ardent de l'histoire", Le Mouvement Social, $\mathrm{N}^{\circ} 111$, abril-junio, París, pp. 48-49.

Labrousse, Ernest (1978), "Georges Haupt, historien français du socialisme international”, Cahiers du monde russe et soviétique, vol. 19, $\mathrm{N}^{\circ} 3$, julioseptiembre, pp. 217-220.

Löwy, Michael (1998), ¿Patrias o planeta? Nacionalismos e internacionalismos. De Marx a nuestros dias, Rosario: Homo Sapiens.

- (2012), "Georges Haupt, internationaliste. Sous l'étoile de Rosa Luxemburg”, Cahiers Jaurès, N²03, enero-marzo, París, pp. 111-119. 
Luxemburg, Rosa (1976), Vive la lutte! Correspondance, 1891-1914, textos reunidos, traducidos y anotados bajo la dirección de Georges Haupt por C. Weill, I. Petit y G. Badia, París: Maspero, Bibliothèque Socialiste.

- (1977), J'étais, je suis, je serai! Correspondance 1914-1919, textos reunidos, traducidos y anotados bajo la dirección de Georges Haupt por G. Badia, I. Petit y C. Weill, París: Maspero, Bibliothèque Socialiste.

Maitron, Jean (1980), "Georges Haupt. Vingt ans après", Le Mouvement Social, $\mathrm{N}^{\circ} 111$, abril-junio, París, pp. 30-32.

- y Georges Haupt (dirs.) (1971), Dictionnaire biographique du mouvement ouvrier international, I, Autriche, París: Éditions Ouvrières.

Marek, Franz (1980), "Georges Haupt et la crise du marxisme", Le Mouvement Social, $\mathrm{N}^{\circ} 111$, abril-junio, París, pp. 52-54.

Montgomery, David (1979), "The Legacy of Georges Haupt", International Labor and Working-Class History, $\mathrm{N}^{\circ} 14-15$, primavera, Cambridge University Press, p. 1.

Negt, Oskar (1978), "Georges Haupt. In Memoriam”, New German Critique, $\mathrm{N}^{\circ} 14$, primavera, Ithaca (NY), Cornell University, pp. 28-30.

Perrot, Michelle (1980), "Georges Haupt. Les tables rondes de la MSH", Le Mouvement Social, $\mathrm{N}^{\circ} 111$, abril-junio, París, pp. 34-36.

Rabinbach, Anson (1980), "Georges Haupt: History and the Socialist Tradition", Le Mouvement Social, $\mathrm{N}^{\circ} 111$, abril-junio, Paris, pp. 75-83.

Rebérioux, Madeleine (1980), "Bibliographie de Georges Haupt", Le Mouvement Social, $\mathrm{N}^{\circ} 111$, abril-junio, París, pp. 255-268.

Robert, Jean-Louis (1988), "Une radiographie du Mouvement social (19601986)", Le Mouvement Social, N 142, enero-marzo, París, pp. 11-30.

Salvati, Mariuccia (2012), "Un historien socialiste du XXe siècle", Cahiers Jaurès, $\mathrm{N}^{\circ}$ 203, enero-marzo, Paris, pp. 27-48.

Vuilleumier, Marc (1980), "Le Haupt-Kolloquium de Zurich", Le Mouvement Social, $\mathrm{N}^{\circ} 111$, abril-junio, París, pp. 64-71.

Weill, Claudie (2012), "Mémoires et heritage", Cahiers Jaurès, N²03, eneromarzo, París, pp. 101-110. 